\title{
Preparing for future waves and pandemics: a global hospital survey on infection control measures and infection rates in COVID-19
}

\author{
Simon Matoori ${ }^{1,2,3^{*}} \mathbb{D}$, Daniel R. Kuritzkes ${ }^{4}$, Yonggeng Goh ${ }^{5}$, Swee Tian Quek ${ }^{5}$, Liang Wang ${ }^{6}$, Ziyan Sun ${ }^{6}$, \\ Fabiano di Marco ${ }^{7,8}$, Daniela Borleri ${ }^{9}$, Sabrina Buoro ${ }^{9}$, Stefano Fagiuoli ${ }^{10}$, Tatiana Ferrari ${ }^{11}$, Marco Rizzi ${ }^{12}$, \\ Federico Raimondi ${ }^{13}$, Simonetta Cesa ${ }^{14}$, Dow-Mu Koh ${ }^{3}$, Johannes M. Froehlich ${ }^{15}$, Sonja Janssen ${ }^{16}$, \\ Bettina Lange ${ }^{17}$, Alexander Egle ${ }^{18}$, Stefan Erb ${ }^{19}$, Erik Mossdorf ${ }^{19}$ and Andreas Gutzeit ${ }^{2 *}$
}

\begin{abstract}
A survey of hospitals on three continents was performed to assess their infection control preparedness and measures, and their infection rate in hospital health care workers during the COVID-19 pandemic. All surveyed hospitals used similar PPE but differences in preparedness, PPE shortages, and infection rates were reported.
\end{abstract}

\section{Introduction}

In the COVID-19 pandemic, the need for personal protective equipment (PPE) strongly increased to protect health care workers (HCWs) within the hospital from infection by COVID-19-positive patients [1]. Although our understanding of the novel coronavirus strain SARS$\mathrm{CoV}-2$ has been rapidly evolving, a detailed understanding on the modes of transmission is still lacking $[2,3]$. To protect HCWs, the World Health Organization and the Centers for Disease Control recommend the use of face masks, eye protection, gowns, medical gloves, frequent hand hygiene, environmental cleaning, and waste management [4]. The most potent protection, respirators which filter out at least 94\% (FFP2, N95) or 99\% (FFP3, N99) of airborne particles, as well as other PPE were quickly in short demand as the pandemic swept around the planet, resulting in shortages in many hospitals with

\footnotetext{
*Correspondence: simon.matoori@umontreal.ca; andreas.gutzeit@hirslanden. ch

${ }^{1}$ Faculté de Pharmacie, Université de Montréal, 2940 Chemin de Polytechnique, Montreal, QC H3T 1J4, Canada

2 Department of Health Sciences and Medicine, University of Lucerne, Lucerne, Switzerland

Full list of author information is available at the end of the article
}

a potential increase in COVID-19 infection risk for HCWs $[5,6]$.

Our hypothesis was that the preparedness and response to the pandemic was different among hospitals, countries, and regions, and resulted in different exposure risk for HCWs in terms of COVID-19 prevalence and PPE availability. The goal of our study was to compare and assess the preparedness, the response, and the infection rate among hospital HCWs of several institutions on three continents by questionnaire.

\section{Methods}

No Institutional Review Board approval or informed patient consent was needed for this survey. The survey was performed between June and August 2020 at eight different institutions: Salzburg (Austria), Wuhan (China), Mannheim (Germany), Bergamo (Italy), Singapore, Hirslanden Klinik in Lucerne (Switzerland), an anonymized institution in the UK, Boston (MA, USA). Sites were recruited by emailing the Division of Infectious Diseases of each hospital. Surveys were sent out by email and reports were received by email.

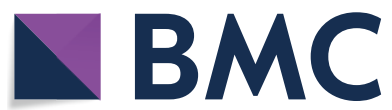

(c) The Author(s) 2021. Open Access This article is licensed under a Creative Commons Attribution 4.0 International License, which permits use, sharing, adaptation, distribution and reproduction in any medium or format, as long as you give appropriate credit to the original author(s) and the source, provide a link to the Creative Commons licence, and indicate if changes were made. The images or other third party material in this article are included in the article's Creative Commons licence, unless indicated otherwise in a credit line to the material. If material is not included in the article's Creative Commons licence and your intended use is not permitted by statutory regulation or exceeds the permitted use, you will need to obtain permission directly from the copyright holder. To view a copy of this licence, visit http://creativecommons.org/licenses/by/4.0/. The Creative Commons Public Domain Dedication waiver (http://creativeco mmons.org/publicdomain/zero/1.0/) applies to the data made available in this article, unless otherwise stated in a credit line to the data. 


\section{Questionnaire}

The surveyed hospitals were given a questionnaire about institutional baseline characteristics and infection control measures for the COVID-19 pandemic of 2020. The questionnaire was answered by an infectious disease expert of the corresponding institution, and included the following topics: (1) Baseline characteristics of the participating hospitals; (2) COVID-19 infection rates among HCWs, (3) Pandemic preparations and trainings for a pandemic with an infectious respiratory disease before the COVID-19 outbreak, (4) Personal protective equipment (PPE) for health care worker with close contact with COVID-19 positive or suspected patients during the COVID-19 pandemic, and (5) various management issues of the COVID-19 pandemic (Additional file 1).

The infection rate was calculated as the number of infected HCWs divided by the total number of HCWs in the hospital. Shortages in PPE were defined as the absence of the PPE article in question. Survey respondents retrieved all hospital infection data reported in this study from their hospital records.

\section{Results}

Baseline characteristics of the surveyed hospitals and COVID-19 infection rates

The overall survey response rate was $100 \%$. No incomplete survey responses were received.

Baseline characteristics of the eight hospitals included in the survey and the COVID-19 case load of their country are shown in Table 1 and Additional file 1: Table S1. Five hospitals are located in Europe (Austria, Germany, Italy, Switzerland, United Kingdom), two in Asia (China, Singapore) and one in North America (United States) (Additional file 1: Fig. S1).

All surveyed hospitals are mid-sized to large tertiary referral centers. The percentage of COVID-19-positive
HCWs varied widely from 0.1 to $8.5 \%$. The two Asian institutions showed low infection rates $(\leq 1 \%)$ despite treating large numbers of COVID-19 positive patients.

\section{Pandemic preparedness before the COVID-19 outbreak}

All hospitals except two (Italy and United Kingdom) reported respiratory infectious disease outbreak preparedness with basic infection control trainings of any kind before the onset of the COVID-19 pandemic (Additional file 1: Table S2).

The institutions in China and Singapore noted that their plan for a pandemic with a respiratory infection was mainly based on the experience from the first SARS epidemic and the resulting policies. While the institution in Italy did not specifically prepare for a pandemic with a respiratory infectious disease, there was a course to prepare for an Ebola outbreak aimed at the Emergency Department in 2019. Furthermore, there was an emergency preparation meeting before the first COVID-19 patient was admitted to the Italian institution.

\section{Personal protective equipment during the COVID-19} outbreak in case of close contact with COVID-19 patients

All surveyed hospitals reported the use of surgical masks or respirators (FFP2/3, N95) and other disposable PPE such as gloves, gowns, and hand disinfectants (Table 2). Disposable caps and goggles were not used in two European hospitals. Other PPE used include face shields, visors, aprons, and air-purifying respirators in aerosolizing procedures. HCWs were trained to put on and use the PPE in all institutions.

Four of the eight surveyed institutions reported shortages in PPE at some point in the pandemic (Additional file 1: Table S3). Masks or respirators were missing for at least a brief period of time at the institutions in Austria, Germany, Italy, and the US. Three of the eight institutions

Table 1 Hospital baseline information and number of infected HCWs and patients

\begin{tabular}{|c|c|c|c|c|c|c|}
\hline Institution & $\begin{array}{l}\text { Total hospital } \\
\text { beds }\end{array}$ & Total HCWs & $\begin{array}{l}\text { Total infected } \\
\text { HCWs }\end{array}$ & $\begin{array}{l}\text { Percentage of } \\
\text { infected HCWs (\%) }\end{array}$ & $\begin{array}{l}\text { Number of treated } \\
\text { COVID-19 patients }\end{array}$ & $\begin{array}{l}\text { Date of } \\
\text { questionnaire } \\
\text { completion }\end{array}$ \\
\hline Salzburg, Austria & 1167 & 3471 & 43 & 1.2 & 170 & June 5, 2020 \\
\hline Wuhan, China & 7000 & 9700 & 100 & 1.0 & 3200 & July 23, 2020 \\
\hline Mannheim, Germany & 1300 & 3719 & 17 & 0.4 & 63 & June 3, 2020 \\
\hline Bergamo, Italy & 1000 & 4705 & 398 & 8.5 & $2141^{a}$ & September 24, 2020 \\
\hline Singapore & 1160 & 7800 & 7 & 0.1 & 887 & June 2, 2020 \\
\hline Lucerne, Switzerland & 220 & 1300 & 6 & 0.4 & 18 & August 10, 2020 \\
\hline UK & 269 & 3900 & 278 & 7.1 & 95 & August 1, 2020 \\
\hline Boston, USA & 793 & 24,000 & 450 & 1.9 & $682^{b}$ & August 18, 2020 \\
\hline
\end{tabular}

${ }^{a}$ Number of hospital-admitted COVID-19 patients (total number in Emergency Department: 4212)

b Until June 30, 2020 
Table 2 Availability of PPE for frontline HCWs during the COVID-19 pandemic

\begin{tabular}{|c|c|c|c|c|c|c|c|c|c|}
\hline \multirow[t]{2}{*}{ Institution } & \multicolumn{2}{|l|}{ Masks } & \multirow{2}{*}{$\begin{array}{l}\text { Disposable } \\
\text { gloves }\end{array}$} & \multirow{2}{*}{$\begin{array}{l}\text { Disposable } \\
\text { gowns }\end{array}$} & \multirow{2}{*}{$\begin{array}{l}\text { Disposable } \\
\text { caps }\end{array}$} & \multirow{2}{*}{$\begin{array}{l}\text { Disposable } \\
\text { goggles }\end{array}$} & \multirow{2}{*}{$\begin{array}{l}\text { Hand } \\
\text { disinfectant }\end{array}$} & \multirow[t]{2}{*}{ Other PPE } & \multirow[t]{2}{*}{ Training } \\
\hline & Type & Duration & & & & & & & \\
\hline $\begin{array}{l}\text { Salzburg, } \\
\text { Austria }\end{array}$ & SM, FFP2, FFP3 & $4 \mathrm{~h}$ & Yes & Yes & Yes & $Y_{e s}{ }^{a}$ & Yes & Face shields & Yes \\
\hline Wuhan, China & SM, N95, KN95 & $4 \mathrm{~h}$ & Yes & Yes & Yes & Yes & Yes & Yes & Yes \\
\hline $\begin{array}{l}\text { Mannheim, } \\
\text { Germany }\end{array}$ & FFP2, FFP3 & $1 /$ shift & Yes & Yes & Yes & Yes & Yes & Aprons & Yes \\
\hline Bergamo, Italy & $\begin{array}{l}\text { SM, FFP2, FFP3, } \\
\text { N95, N99, KN95 }\end{array}$ & 1-2/shift & Yes & Yes & Yes & Yes & Yes & Face shields & Yes \\
\hline Singapore & SM, N95 & $4-5 h$ & Yes & Yes & Yes & Yes & Yes & $\begin{array}{l}\text { Powered } \\
\text { air-purifying } \\
\text { respirator } \\
\text { (interventional } \\
\text { radiology) }\end{array}$ & Yes \\
\hline $\begin{array}{l}\text { Lucerne, Swit- } \\
\text { zerland }\end{array}$ & SM, FFP2 & $1 /$ shift & Yes & Yes & No & Yes & Yes & No & $Y_{e s}^{b}$ \\
\hline UK & SM, FFP2, FFP3 & $1 /$ shift & Yes & Yes & Yes & No & Yes & Face shields & Yes $^{c}$ \\
\hline Boston, USA & N95 (fitted) & 1/shift (8-12 h) & Yes & Yes & No & $Y_{e s}{ }^{a}$ & Yes & $\begin{array}{l}\text { Personal respi- } \\
\text { rators (if unable } \\
\text { to use N95), } \\
\text { face shields }{ }^{\text {a }}\end{array}$ & Yes \\
\hline
\end{tabular}

SM surgical masks

${ }^{\text {a }}$ Reused after disinfection

${ }^{b}$ Only HCWs in risk areas (COVID-19 ward, emergency department, intensive care unit)

c Only frontline staff with contact with COVID-19 patients

reported that disposable gowns were not available during the entire time of the pandemic. Single institutions further reported shortages in gloves and disinfectants, and the need for rationing PPE to avoid shortages.

\section{Management of the pandemic}

Infectious disease specialists were in charge of the management of the pandemic in all surveyed hospitals except for the one in the UK where non-specialized physicians were responsible (Additional file 1: Table S4). All hospitals put a task force in charge of coordinating the safety measures to reduce viral spread in the hospital, and implemented zoning (i.e., areas designated for suspected and confirmed COVID-19 patients), grouping COVID19-positive patients (cohorting), hygiene trainings, and restrictions for visitors. Masking of HCWs in the entire hospital was mandated by all hospitals except for the one in Salzburg, where it was recommended. Visitor restrictions were put in place in all surveyed hospitals, with two hospitals allowing no visitors and two only allowing compassionate visits.

\section{Discussion}

In this study, we evaluated the preparedness, the management, and the infection rate of hospital HCWs of the COVID-19 pandemic of eight hospitals located in Europe, Asia, and North America. While most hospitals were prepared for a pandemic with a respiratory disease, there were shortages in several PPE, namely masks and gowns. The percentage of COVID-19-positive hospital workers ranged from 0.1 to $8.5 \%$. Notably, the Asian hospitals reported no shortages in surgical masks or respirators and showed low infection rates $(\leq 1 \%)$ despite high numbers of treated COVID-19 patients. Without pointing fingers, this survey helps us identify key aspects of preparedness in terms of planification and PPE item stockage, in order to be better prepared for future waves of COVID-19 and other pandemics with respiratory viruses.

The low infection numbers despite high caseloads in Asian hospital may be explained by the experience with the SARS epidemic in 2002/2003 which mainly affected Asian countries such as China, Singapore, Vietnam, and Hong Kong. Hospital transmission accounted for a 22 to $57 \%$ of SARS cases [7], and was primarily related to inappropriate or missing PPE, hand disinfection, and hospital personnel education (e.g., removal of contaminated PPE) [8]. As a result, these countries prepared sophisticated plans to manage future pandemics, mandating training hospital personnel for pandemics with respiratory pathogens, stockpiling PPE, and further measures such as zoning [9]. As no shortages in masks and respirators were reported by these hospitals, their stockpiling has likely contributed to the low infection 
rates in these hospitals, which underlines their importance in protecting HCWs from COVID-19 patients.

In our survey, countries with less exposure to the first SARS epidemic, namely in Europe and the US, were less prepared in terms of personnel training and/or PPE stockpiling, and experienced more PPE shortages and higher numbers of infected hospital HCWs. However, hospitals showed a steep learning curve, adopting measures such as universal masking for hospital personnel and proving their usefulness for infection control [10-12].

As we prepare for the next waves of COVID-19, we have learned that universal masking of hospital personnel with surgical masks, immediately isolating COVID19-positive patients, and the use of highly protective PPE (respirators, eye protection, gowns) in contact with COVID-19 patients is of high utility to protect HCWs [4, 13]. As some of these insights were already available after the SARS epidemic and improved the response of the surveyed Asian hospitals to the COVID-19 pandemic, it is instrumental for hospitals to learn from each other's experiences and to cooperate to improve hospital infection control in future waves of COVID-19 and other pandemics. Based on the information of this survey, it will be essential to either stock higher amounts of PPE or to have the capacity to produce or recycle PPE locally to be prepared for future disruptions in supply chains.

This study has several limitations. Most importantly, we cannot determine if the COVID-19 positive hospital HCWs were infected in the hospital or outside. Indeed, the true extent of COVID-19 is difficult to assess [14, 15]. Another limitation of the study is that the questionnaire was filled out when some countries were still in the first wave while others were past the first wave (e.g., China). Furthermore, there might be a selection bias as most hospitals were selected based on previous collaborations. Another limitation is that all surveyed hospitals are located in upper-middle to high-income countries. Finally, some surveyed European hospitals treated low numbers of COVID-19 patients, complicating the evaluation of their true preparedness.

In this survey, all responding hospitals in Asia, Europe, and North America reported the use of recommended PPE but the degree of preparedness, PPE shortages, and infection rate among hospital HCWs varied widely. Our study highlights the importance of universal masking of HCWs with surgical masks, immediately isolating COVID-19-positive patients, and the use of highly protective PPE (respirators, eye protection, gowns). To prepare for the next waves of COVID-19 and future pandemics, we further urge hospitals to learn from each other and to cooperate to improve infection control.

\section{Supplementary Information}

The online version contains supplementary material available at https://doi. org/10.1186/s13756-021-01029-z.

Additional file 1: Supplementary Figure and Tables.

\section{Acknowledgements}

We thank Health Care Workers worldwide for their efforts during the COVID-19 pandemic.

\section{Authors' contributions}

SM, SE, and AG prepared the questionnaire and wrote the original draft of the manuscript. All authors contributed to the data presented in this manuscript, edited the manuscript, and approved the final version of the manuscript.

Funding

All authors report no financial support relevant to this manuscript.

\section{Availability of data and materials}

All relevant data and material are included in the main text and the supporting information of this manuscript.

\section{Declarations}

Ethics approval and consent to participate

Ethics approval was waived for this survey.

\section{Consent for publication}

All authors consented to the publication of this manuscript.

\section{Competing interests}

The authors declare that they have no competing interests.

\section{Author details}

${ }^{1}$ Faculté de Pharmacie, Université de Montréal, 2940 Chemin de Polytechnique, Montreal, QC H3T 1 J4, Canada. ${ }^{2}$ Department of Health Sciences and Medicine, University of Lucerne, Lucerne, Switzerland. ${ }^{3}$ Department of Radiology, Paracelsus Medical University, Salzburg, Austria. ${ }^{4}$ Division of Infectious Diseases, Brigham and Women's Hospital, Boston, MA, USA. ${ }^{5}$ Department of Diagnostic Imaging, National University Hospital, Singapore, Republic of Singapore. ${ }^{6}$ Department of Radiology, Tongji Hospital, Tongji Medical College, Huazhong University of Science and Technology, Wuhan, China. ${ }^{7}$ Pneumology Unit, Papa Giovanni XXIII Hospital, Bergamo, Italy. ${ }^{8}$ Health Sciences Department, University of Milan, Milan, Italy. ${ }^{9}$ Occupational Medicine Unit, Papa Giovanni XXIII Hospital, Bergamo, Italy. ${ }^{10}$ Quality Management Unit, Papa Giovanni XXIII Hospital, Bergamo, Italy. ${ }^{11}$ Gastroenterology, Hepatology and Liver Transplantation, Department of Medicine, Papa Giovanni XXIII Hospital, Bergamo, Italy. ${ }^{12}$ Infectious Diseases Unit, Papa Giovanni XXIII Hospital, Bergamo, Italy. ${ }^{13}$ Respiratory Unit, Department of Medicine, Papa Giovanni XXIII Hospital, Bergamo, Italy. ${ }^{14}$ Department of Health and Social Care Professions, Papa Giovanni XXIII Hospital, Bergamo, Italy. ${ }^{15}$ Clinical Research Group, Klus Apotheke Zurich, Zurich, Switzerland. ${ }^{16}$ Clinic of Radiology and Nuclear Medicine, University Medical Center Mannheim, University of Heidelberg, Mannheim, Germany. ${ }^{17}$ Hospital Hygiene Unit, University Medical Center Mannheim, University of Heidelberg, Mannheim, Germany. ${ }^{18} \mathrm{III}$ rd Medical Department with Hematology and Medical Oncology, Hemostaseology, Rheumatology and Infectious Diseases, Oncologic Center, Paracelsus Medical University, Salzburg, Austria. ${ }^{19}$ Department of Infectious Diseases, Hirslanden Klinik St. Anna, Lucerne, Switzerland.

Received: 12 October 2021 Accepted: 24 October 2021

Published online: 20 December 2021 


\section{References}

1. Kamerow D. Covid-19: the crisis of personal protective equipment in the US. BMJ. 2020;369:1367.

2. Meselson M. Droplets and aerosols in the transmission of SARS-CoV-2. N Engl J Med. 2020;382(21):2063.

3. Fennelly KP. Particle sizes of infectious aerosols: implications for infection control. Lancet Respir Med. 2020;8(9):914-24.

4. Bartoszko JJ, Farooqi MAM, Alhazzani W, Loeb M. Medical masks vs N95 respirators for preventing COVID-19 in healthcare workers: a systematic review and meta-analysis of randomized trials. Influenza Other Respi Viruses. 2020;14(4):365-73.

5. Ranney ML, Griffeth V, Jha AK. Critical supply shortages - the need for ventilators and personal protective equipment during the Covid-19 pandemic. N Engl J Med. 2020;382(18):E41.

6. Livingston E, Desai A, Berkwits M. Sourcing personal protective equipment during the COVID-19 pandemic. JAMA. 2020;323(19):1912-4.

7. Chowell G, Abdirizak F, Lee S, et al. Transmission characteristics of MERS and SARS in the healthcare setting: a comparative study. BMC Med. 2015;13(1):210.

8. Shaw K. The 2003 SARS outbreak and its impact on infection control practices. Public Health. 2006;120(1):8-14.

9. Goh Y, Chua W, Lee JKT, et al. Operational strategies to prevent coronavirus disease 2019 (COVID-19) spread in radiology: experience from a Singapore Radiology Department after severe acute respiratory syndrome. J Am Coll Radiol. 2020;17(6):717-23.

10. Wang X, Ferro EG, Zhou G, Hashimoto D, Bhatt DL. Association between universal masking in a health care system and SARS-CoV-2 positivity among health care workers. JAMA. 2020;324(7):703.

11. Klompas M, Morris CA, Sinclair J, Pearson M, Shenoy ES. Universal masking in hospitals in the COVID-19 era. N Engl J Med. 2020;382(21):e63.

12. Gutzeit A, Li Q, Matoori S, Li B, Wang L. What can European radiologists learn from the outbreak of COVID-19 in China? A discussion with a radiologist from Wuhan. Eur Radiol. 2020;30(7):3609-11.

13. Qaseem A, Etxeandia-Ikobaltzeta I, Yost J, et al. Use of N95, surgical, and cloth masks to prevent COVID-19 in health care and community settings: living practice points from the American College of Physicians (version 1). Ann Intern Med. 2020;178:M20-3234.

14. Matoori S, Khurana B, Balcom MC, Koh DM, Froehlich JM, Janssen S, Kolokythas O, Gutzeit A. Intimate partner violence crisis in the COVID19 pandemic: how can radiologists make a difference? Eur Radiol. 2020;30(12):6933-6.

15. Matoori S, Khurana B, Balcom MC, Froehlich JM, Janssen S, Forstner R King AD, Koh DM, Gutzeit A. Addressing intimate partner violence during the COVID-19 pandemic and beyond: how radiologists can make a difference. Eur Radiol. 2021;31(4):2126-31.

\section{Publisher's Note}

Springer Nature remains neutral with regard to jurisdictional claims in published maps and institutional affiliations.

Ready to submit your research? Choose BMC and benefit from:

- fast, convenient online submission

- thorough peer review by experienced researchers in your field

- rapid publication on acceptance

- support for research data, including large and complex data types

- gold Open Access which fosters wider collaboration and increased citations

- maximum visibility for your research: over $100 \mathrm{M}$ website views per year

At $\mathrm{BMC}$, research is always in progress.

Learn more biomedcentral.com/submissions 